\title{
Evaluation of Alternative Irrigation Technologies based upon Applied Water and Simulated Yields*
}

\author{
Francisco L. Santos \\ Department of Rural Engineering, University of Évora, Apartado 94, 7001 Evora Codex, Portugal \\ (Received 23 December 1996; accepted in revised form 8 October 1997)
}

Adequate estimates of yields under comparable amounts of infiltrated water of different irrigation systems are essential for evaluation and adoption of irrigation decisions. A simulation model, crop evapotranspiration and Young's criteria for subjective probability estimates from objective data were used to simulate water management regimes for pressurized and surfaceirrigation systems. Historical climatic data, representative soil series and irrigation technologies for Central Arizona were considered in the simulations. Comparable spatial and average yields for drip, graded furrow, level furrow and level basin systems with similar distribution uniformity of applied water were predicted when each irrigation system infiltrates to the same depth in the low-quarter section of the irrigated field as the average of that quarter, to meet seasonal crop evapotranspiration. This implies that a similar fraction of the field $(87.5 \%)$ is adequately irrigated in each case. Irrigation reuse systems are advisable to achieve comparable, and high, water application efficiencies with furrow systems. Applied water and simulated yields were influenced by the uniformity distribution of the irrigation technologies showing that the model can be used to explore the implications of design and management decisions. The applied water and simulated yields can be used as inputs in economic models to aid selection of farm irrigation systems.

(C) 1998 Silsoe Research Institute

\section{Introduction}

Irrigated agriculture operates today in a changing environment. New government policies restrict groundwater pumping to protect aquifers, establish limits on applied water to reduce the leaching of nitrogen into 1996

*Presented at AgEng 96, Madrid, Spain, 23-26 September ground-water supplies for urban users and/or require the grower to maintain a prescribed irrigation efficiency. To meet these increasing demands on their businesses, growers have turned to water-conserving irrigation technologies, including more intensive management, to survive and prosper. Yet the strategic need to change from traditional to new irrigation technologies also creates additional uncertainty for the decision maker.

Solomon ${ }^{1}$ reviewed the complexity of evaluating irrigation technologies, emphasizing that biological as well as physical factors such as crop production practices, soils, topography, water supply and climate should be considered. Nakayama and Bucks ${ }^{2}$ emphasize the multidimensional aspects of evaluating irrigation systems. They argue that costs and quality issues associated with the technology, land and water are the critical concerns in any analysis. Others (e.g. Hill and Keller ${ }^{3}$ ) have argued that due to the complexity of these decision problems, irrigation technology choices generally are made by intuition and not by rigorous analytical techniques. Growers and decision makers, according to these authors, may not explicitly follow Solomon's or Nakayama and Bucks' guidelines but implicitly they take into consideration many of the factors outlined above. They usually evaluate the gamut of the available and relevant irrigation technologies before deciding whether or not to substitute a new system for the existing irrigation system. Irrigation specialists ${ }^{4,5}$ argue, however, that these usually compare a new, well-designed system against the traditional sloped furrow system. As a result, the economic superiority of the new system in assured a priori.

A method of analysing these complex decisions in irrigated agriculture is through the development of an adequate model which permits evaluation and exploration of the consequences brought about by different technologies and design decisions. The object of the present study is to test the suitability of a proposed model to provide objective comparison of alternative irrigation technologies by simulating their performance in terms of 
applied water and corresponding yields. The model allows a procedure (proposed in successive phases) by which the planner and designer can evaluate and compare alternative assumptions on the uniformity of water application and fraction of the field area adequately irrigated by either surface (graded furrow, level furrow and level basin systems) or pressurized systems (drip irrigation).

The procedure is applied to a farm in Central Arizona, USA. Space considerations limit the discussion to one crop, cotton and one soil series, Casa-Grande $\left(\operatorname{Santos}^{6,7}\right)$. A surface irrigation simulation (SRFR) sub-model ${ }^{8}$ and derived management-design charts ${ }^{7}$ are used to simulate water-management regimes and generate the spatial water distribution of infiltrated depths and water applied for surface irrigation systems. For pressurized systems, a water distribution simulation sub-model is used to generate the spatial water distribution of infiltrated depths and water applied. The output of both sub-models provides the input to a crop production sub-model which generates spatially varied yield estimates and the expected yield for the field.

\section{Literature review}

Previous attempts at economic design and evaluation of irrigation systems have emphasized the necessity of taking into account the effect of uniformity of water application on yields and applied water. The relationship between water application and the uniformity of infiltrated water over the field is described by Seginer, ${ }^{9-11}$ Warrick and Gardner, ${ }^{12}$ Letey et al., ${ }^{13}$ Yitayew et al. ${ }^{14}$ and Warrick and Yates. ${ }^{15}$ All have emphasized the importance of water management as a critical factor in meeting crop water demands.

The quantity of infiltrated water and uniformity are dependent on technology, management decisions and soil characteristics. For surface irrigation systems, the important hydraulic variables are inflow rate, length of water run over the field, time of irrigation water cut-off, surface resistance of water flow, field slope and the infiltration characteristics of the soil. ${ }^{16}$ The combination of these variables may result in non-uniformity from varying intake opportunity time and infiltration rate throughout the irrigated field. For pressurized systems such as sprinkler and drip, non-uniformity results from hydraulic design, differences in sprinkler and emitter flow rates, manufacturing characteristics, clogging and temperature variations ${ }^{17,18}$ which cause non-uniform water application over the field.

The effect of non-uniformity is the same regardless of the factors and technology causing it. It affects the amount of water applied ${ }^{7,10,19}$ and hence the corresponding yields. Due to this lack of uniformity, part of the surface area is adequately irrigated while others are not. In the adequately irrigated area, an excess of water can arise, leading to poor soil aeration, leaching of mineral nutrients and lower yields. In deficit areas, those receiving insufficient irrigation water, a drop in yield is expected due to the inadequate supply of water for the crop. $^{20}$

According to the literature, ${ }^{20-23}$ the relationships between crop yield $(Y)$ and water $(w)$ can range from linear to curvilinear response functions. These variations are influenced by the type of water parameter that is chosen, its measurement or estimation accuracy and the varied influences associated with the site and production conditions. When yields are limited by transpiration $(T)$, a strong correlation usually occurs between cumulative seasonal dry matter and cumulative seasonal transpiration. ${ }^{24}$ With the close relationship between $T$ and evapotranspiration $(E T)$, dry matter and grain yields are usually strongly correlated with cumulative crop $E T$, and the relationship is one which tends to pass through or very near the origin. ${ }^{22}$

When irrigation systems are operated to supply sufficient water for plants to meet the day-to-day evaporative demand and with a frequency that maintains a high soil water potential in the upper root zone, irrigation specialists generally agree that crop $E T$ is affected little by the method of irrigation. ${ }^{23}$ They conclude that the advantages of one method over another may not be determined by differences in total irrigation water supplied but by the adequacy and effectiveness with which crop requirements can be met throughout the irrigated field. Although ET is the field-level water parameter associated most directly with yield, the depth of field water $(w)$ supplied represents water purchased and is of most concern to planners and irrigators. ${ }^{21}$

The above suggest that there is a definite possibility of achieving comparable yields from different irrigation technologies when comparable amounts of water are applied by these technologies to effectively meet crop ET. With crop requirements met in a similar fraction of the irrigated field, any superiority of one system over another is then merely the result of too much or too little water applied, with the fault lying on the management, not on the method of irrigation. Therefore, the uniformity of distribution of infiltrated depths becomes the critical issue when comparing yields from different technologies. Because water applied is calculated based on potential ET and non-uniformity of infiltrated water increases the water application, the important issue is the amount of water applied and infiltrated and the impact of its spatial distribution on crop yields. 


\section{The theoretical simulation model}

The proposed simulation model outlined in Fig. 1 is an attempt to integrate three sub-models into a practical general, analytical framework aimed at defining criteria for objective comparison of alternative irrigation systems. The three sub-models are (1) SRFR surface irrigation simulation; (2) water distribution simulation and (3) crop production simulation. Each of these sub-models is considered in turn.

\subsection{SRFR surface irrigation simulation sub-model}

For furrow and level basin systems, whose uniformity of infiltrated water depends upon the spatial variability of the soil and the hydraulics of the irrigation system, the SRFR surface irrigation model developed by Strelkoff ${ }^{8}$ was used to simulate the hydraulics of irrigation. The SRFR model is based on numerical solution of volume and time-integrated partial differential equations expressing the physical principles of conservation of mass and conservation of momentum. The assumption of a hydrostatic pressure distribution in the surface stream leads to the Saint Venant equations governing unsteady, nonuniform flow in an open channel. ${ }^{25}$ Verification of the solutions of the Saint Venant equations and the derived zero-inertia formulation used in SRFR, with border and furrow field measurements are reported in Katopodes and Strelkoff ${ }^{26}$ and Strelkoff and Souza, ${ }^{16}$ respectively, and with level basin field measurements in de Sousa et $a l^{27,28}$

SRFR is a predictive tool to evaluate current surface irrigation systems, develop optimum management practices and improve design criteria. It assumes that the inflow of water is distributed evenly across the width of the strip of field to which water is introduced. Water is applied at a known volumetric rate, and the strip possesses known roughness and infiltration characteristics as well as known bottom configuration, length and downstream-boundary conditions. The model uses the Kostiakov infiltration equation ${ }^{29}$ to represent the intake characteristic of the soil at each irrigation and whose constants, which define several soil parameters, may be

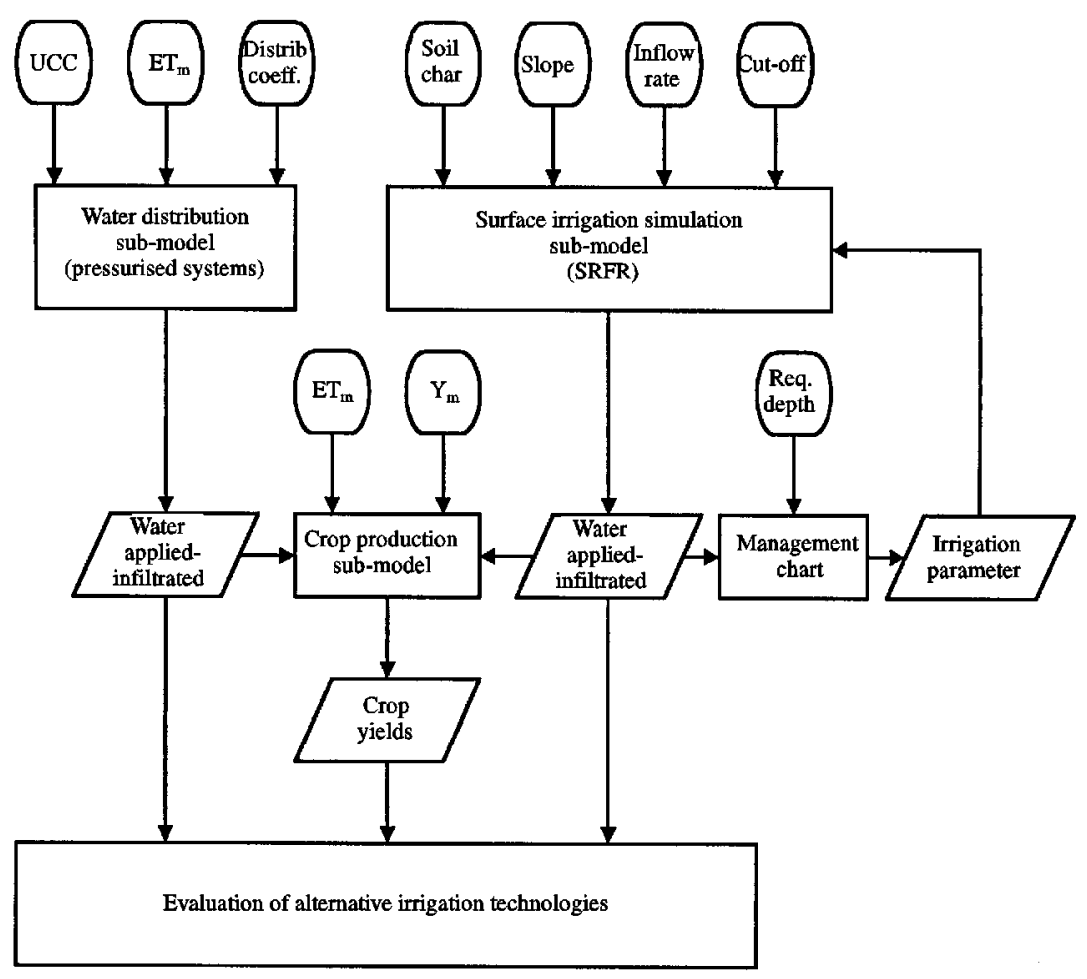

Fig. 1. An integrated model to estimate yields and applied water for evaluation of alternative irrigation technologies. The parameters inscribed in the circles represent inputs to the sub-models. UCC $=$ Christiansen uniformity coefficient; $E T_{m}=$ maximum $_{\text {crop }}$ evapotranspiration; Dist. coeff. = distribution coefficient, ratio of a required depth (Req. depth) to the mean irrigation application; Soil chart. = Soil characteristics such as infiltration and wetted perimeter; $Y_{m}=$ maximum yield. Irrigation parameters are inflow rate $\left(q_{\text {in }}\right)$ and cut-off time ( $\left.t_{c o}\right)$ taken off the management chart (Fig. 2) and the required depth of application 
defined using the unique Soil Conservation Service ${ }^{30}$ intake families equation, ${ }^{29}$ described as follows:

$$
F=\mathrm{a} T^{\mathrm{b}}+\mathrm{c}
$$

where $F$ is the cumulative intake (mm), $T$ the time that water is in contact with the soil $(\mathrm{min})$, and a $\left(\mathrm{mm} / \mathrm{min}^{\mathrm{b}}\right)$, $\mathrm{b}$ and $\mathrm{c}(\mathrm{mm})$ are constants.

The hydraulic calculations in SRFR are based on the Manning equation, ${ }^{31}$ which includes a coefficient $(n)$ that expresses the flow retardance effects of different boundary conditions, which vary with management operations which alter the surface. The duration of time for which water is on the soil surface, with the opportunity to infiltrate, is calculated using the movement of the wave during stream advance and recession.

The model outputs include infiltrated depths, volume of runoff and water application efficiency and various distributions indices. ${ }^{7,8}$ It also computes longitudinal variation of depth and discharge along the length of the surface at a sequence of times after the start of the irrigation. With estimated values of wetted perimeter and opportunity time, the ultimate post-irrigation longitudinal distribution of infiltrated water depth is calculated.

By varying inflow rates $\left(q_{i n}\right)$ and cut-off times $\left(t_{c o}\right)$, SRFR generates hypothetical irrigation data for given field conditions. Figure 2 presents the managementdesign chart, a contour map of grid points of the low-quarter average depths of water infiltrated $(L Q)$ and the corresponding Christiansen uniformity coefficients $(U C C)$, average depth infiltrated minus the average deviation from this depth, divided by the average depth infiltrated. Both parameters were obtained for Casa-

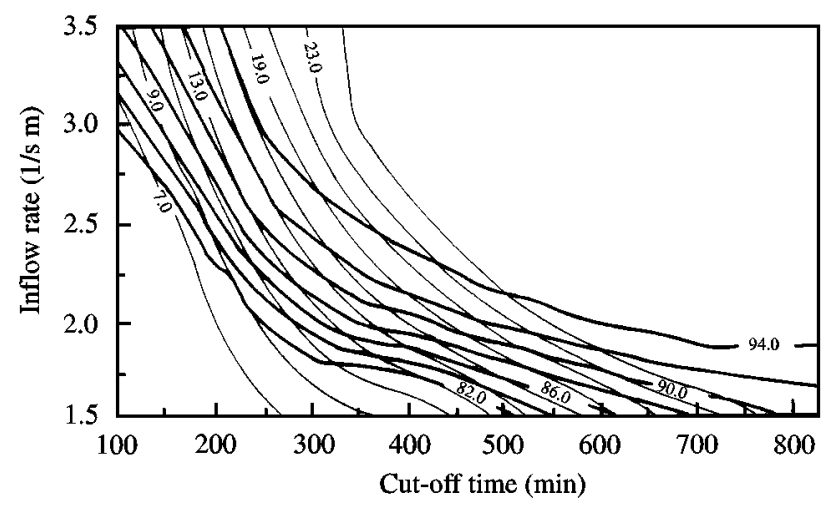

Fig. 2. Management-design chart for level basin irrigation systems. The chart represents relationships of inflow rate $\left(q_{\text {in }}\right)$ to cut-off time ( $\left.t_{c o}\right)$ for various values of irrigation uniformity (thick lines, numbers in percent) as characterized by Christiansen's uniformity coefficient (UCC) and depth of irrigation infiltrated in the low-quarter of the field (thin lines, numbers in $\mathrm{cm}$ ). The curves are contour lines through points of equal uniformity and depth obtained for Casa-Grande soil
Grande soil infiltration characteristics and level basin irrigation system by running SRFR for various levels of inflow rate $\left(q_{i n}\right)$ and cut-off time $\left(t_{c o}\right)$.

To explore implications of design and management decisions on irrigation performance, applied and infiltrated water in incremental sections of the surfaceirrigated fields, two distinct $U C C$ were selected from the charts to correspond to management options, I and II. Management option I represents the highest uniformity possible to obtain from the chart for the irrigation system and management II the lowest possible, while both satisfy the required average depth of irrigation in the low quarter of the field. A desired management allowed deficiency of $50 \%$ of the soil available water ${ }^{29}$ and an average cotton rooting depth of $120 \mathrm{~cm}$ suggested an average irrigation depth of $9.5 \mathrm{~cm}$ in the low-quarter. With this information, relevant levels of $q_{i n}$ and $t_{c o}$ were selected from the design charts and further simulations with SRFR were performed to obtain the value of irrigation parameters and the water actually applied and infiltrated in incremental sections of the irrigated field. Table 1 summarizes the selected design and performance variables for this particular case and presents the generated measures of water distribution and efficiency: the potential efficiency of the low-quarter (PELQ), ratio of average $L Q$ depth to the average depth of water applied, and the lowquarter distribution uniformity $(L Q D U)$, ratio of the average $L Q$ depth of irrigation water to the average depth infiltrated.

\subsection{Water distribution simulation sub-model}

For pressurized irrigation systems such as drip irrigation, designed to avoid surface ponding of water and horizontal surface flow, the uniformity of infiltrated water equals the uniformity of application..$^{23}$ Beginning with the experiments carried out by Hart and Reynolds, ${ }^{32}$ who concluded that the normal distribution is an appropriate function to describe the distribution of water from sprinkler irrigation systems, a great effort has been made to test, confirm and predict other appropriate distribution functions for pressurized systems. Warrick et al. ${ }^{33}$ presented methods for calculating the performance parameters for normal, lognormal, uniform and specialized power functions. Heerman et al., ${ }^{34}$ after fitting several sets of data to normal, lognormal, uniform and specialized power functions concluded that the normal distribution is an appropriate function to describe the distribution of centre-pivot systems. Sammis and $\mathrm{Wu}^{35}$ and $\mathrm{Wu}^{36}$ also conclude that emitter flows of drip and micro-irrigation systems can be expressed as a normal distribution.

According to Hart and Reynolds ${ }^{32}$ the cumulative frequency curve (S-curve) of the normal distribution 
Table 1

Irrigation system performance under alternative management options

\begin{tabular}{|c|c|c|c|c|c|c|c|c|c|c|}
\hline \multicolumn{11}{|c|}{ Casa-Grande soil, intake family $0 \cdot 80$} \\
\hline $\begin{array}{l}\text { Irrigation } \\
\text { system }\end{array}$ & $\begin{array}{c}\text { Irrigation } \\
\text { management } \\
\text { option }\end{array}$ & $\begin{array}{l}\text { Inflow } \\
\text { rate } \\
l / s\end{array}$ & $\begin{array}{l}\text { Cut-off } \\
\text { time } \\
\text { min }\end{array}$ & $\begin{array}{l}\text { Applied } \\
\text { depth } \\
\text { cm }\end{array}$ & $\begin{array}{l}\text { Infiltr. } \\
\text { depth } \\
\quad \text { cm }\end{array}$ & $\begin{array}{l}\text { Runoff } \\
\text { depth } \\
\text { cm }\end{array}$ & $\begin{array}{c}P E L Q \\
\%\end{array}$ & $\begin{array}{c}U C C \\
\%\end{array}$ & $\underset{\%}{L Q D U}$ & $\begin{array}{l}\text { Required } \\
\text { depth } \\
\text { cm }\end{array}$ \\
\hline Graded furrow & $\mathrm{I}$ & $3 \cdot 0$ & 336 & $25 \cdot 2$ & $10 \cdot 2$ & $15 \cdot 1$ & 38 & 95 & 94 & $9 \cdot 5$ \\
\hline Graded furrow & II & $1 \cdot 2$ & 592 & $17 \cdot 8$ & $10 \cdot 7$ & $7 \cdot 0$ & 53 & 90 & 89 & $9 \cdot 5$ \\
\hline Level furrow & I & $2 \cdot 8$ & 297 & $20 \cdot 8$ & $12 \cdot 0$ & $8 \cdot 8$ & 45 & 84 & 79 & $9 \cdot 5$ \\
\hline Level furrow & II & $1 \cdot 2$ & 536 & $16 \cdot 6$ & $12 \cdot 9$ & $3 \cdot 8$ & 57 & 79 & 74 & $9 \cdot 5$ \\
\hline Level basin & $\mathrm{I}$ & $3 \cdot 3$ & 135 & $11 \cdot 2$ & $11 \cdot 2$ & $0 \cdot 0$ & 85 & 89 & 85 & $9 \cdot 5$ \\
\hline Level basin & II & $2 \cdot 0$ & 256 & $12 \cdot 8$ & $12 \cdot 8$ & $0 \cdot 0$ & 73 & 82 & 74 & $9 \cdot 5$ \\
\hline
\end{tabular}

UCC, Christiansen uniformity coefficient; PELQ, potential efficiency of low-quarter; LQDU, low-quarter distribution efficiency.

shows that the range of depth of infiltrated water $(w)$ data following the distribution varies from $H_{b}+3 \sigma$ to $H_{b}-3 \sigma$, where $H_{b}$ is the depth of water applied to the ground and $\sigma$ the standard deviation of application depth. In other words, $0 \%$ of the total area receives more than $H_{b}+3 \sigma$ and $100 \%$ of the area receives more than $H_{b}-3 \sigma$. Any depth of required water $H_{r}$ can be expressed as $H_{r}=H_{b}+\alpha \sigma$, for values of $\alpha$ between +3 and -3 .

With this type of distribution, and according to Warrick et $a l^{33}$ Christiansen's uniformity coefficient $(U C C)$, given by the expression

$$
U C C=\left(1-\frac{\sum\left|w-H_{b}\right|}{H_{b} n}\right) \times 100
$$

is related to the coefficient of variation $(C V)$, defined as $C V=\sigma / H_{b}$, by means of the equation

$$
U C C=100-0 \cdot 798 C V
$$

where $n$ is the number of values for infiltrated water $(w)$ in the distribution. One can decide what fraction of the irrigated area $(a)$ is well-watered, i.e. the fraction that receives at least the intended required depth $H_{r}$. For an irrigation system with a determined $U C C$, when a depth $H_{b}$ is applied to a field and an average depth $\bar{H}$ infiltrates, the water deficit which a fraction of the irrigated surface suffers depends on $U C C$, on the relationship between $\bar{H}$ and the depth required, $H_{r}$, and the proportion of area adequately irrigated or overirrigated $(a)$, which receives a quantity equal or superior to $H_{r}$. Values of $(a)$ are obtained from statistical tables ${ }^{32}$ for the normal distribution according to values of $\alpha$.

When the mean irrigation depth $\bar{H}$ is equal to the daily evapotranspiration $(E T), 50 \%$ of the field is under deficit irrigation. As the mean irrigation application is increased compared with $E T$ or $E T / \bar{H} \leqslant 1$, a smaller percentage of the area is in deficit. Using the cumulative frequency curves (S-curves) of Hart and Reynolds ${ }^{32}$ to relate the relative irrigation depth (percent of the mean irrigation depth) to the fraction of the field area receiving at least that depth, and with a specially created computer program the mean relative deficit evapotranspiration over the total area can be computed for different values of $\bar{H} / E T$ and the spatial distribution of infiltrated depths obtained.

To explore implications of drip design and management decisions comparable with the ones taken above for surface irrigation, i.e. infiltrate the same required depth of water as in the low-quarter of the field average while irrigating with similar uniformity, the normal distribution function for the spatial distribution of drip irrigation depths was assumed and cumulative frequency curves ${ }^{32}$ were used for the purpose. For a particular drip irrigation uniformity, the seasonal mean application depth was calculated by assuming that the average depth in the low-quarter of the field $(87.5 \%$ of the area adequately irrigated) met or exceeded the irrigation requirement $\left(E T_{\text {crop }}\right)$. The irrigated area was then divided into sections and for each section of the field the quantity of water actually infiltrated was estimated as the product of the relative depth and the seasonal mean application depth. This procedure was used for uniformity coefficients of $0.88,0.92,0.94$ and 0.96 and it established the standard for comparing the applied and infiltrated depths of drip irrigation systems with similarly managed surface irrigation systems. The cumulative frequency S-curve of a normal distribution for the coefficient of variation of 0.30 is plotted non-dimensionally as shown in Fig. 3. The plot relates the relative irrigation depth $X$ which is the ratio of a required depth $H_{r}$ to the mean irrigation application $\bar{H}\left(X=H_{r} / \bar{H}\right)$ to the fraction of the field area $(a)$ receiving at least that depth. 


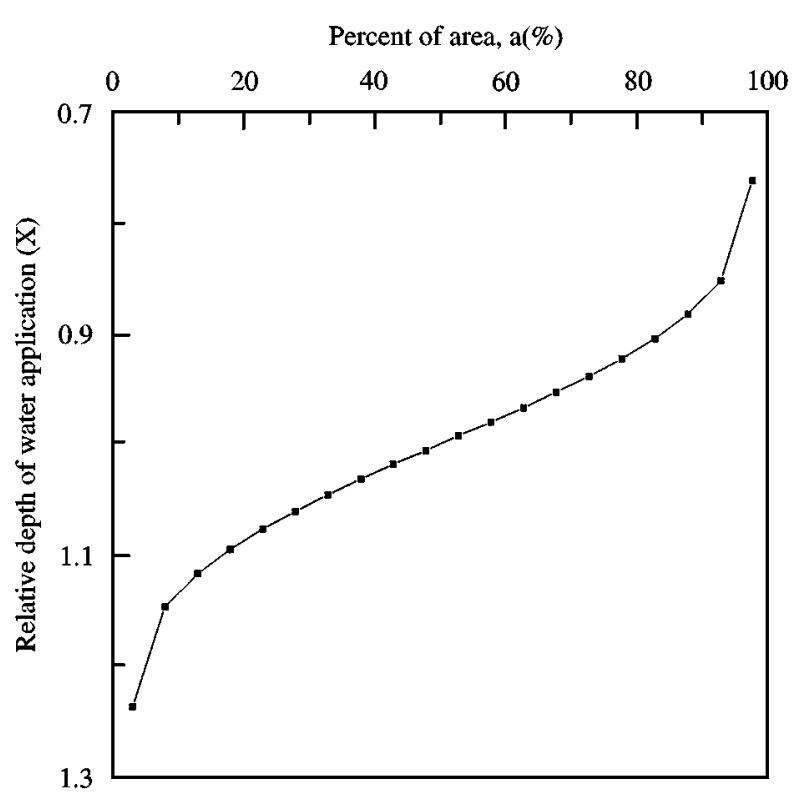

Fig. 3. The cumulative frequency $S$-curve of a normal distribution for the coefficient of variation $(\mathrm{CV})$ of $0 \cdot 30$ plotted non-dimensionally as the relationship between the percent (fraction) of area (a) adequately irrigated and the relative irrigation depth $(X)$ which is the ratio of a required depth $H_{r}$ to the mean irrigation application $\bar{H}$

\subsection{Crop production sub-model}

The deficit area will receive less irrigation than required and the effects of this on yield can be shown by a crop response model. ${ }^{35,37,38}$ Expected field-level yields under non-uniform application conditions requires (1) knowledge of infiltrated depths at different points over the field and (2) a functional relationship between yields and infiltrated water (i.e. production function). Following the work of Hill and Keller ${ }^{3}$ and considering water to be the only limiting factor, expected yield $(Y)$ can be expressed as

$$
\bar{Y}=\int_{0}^{\infty} y(w) f(w) d w
$$

where $y(w)$ is the relationship between yield and applied water and $f(w)$ is any assumed distribution function that estimates the water distribution over the field. For computational convenience, the distribution function can be approximated by a discrete distribution and the expected yield calculated as

$$
\bar{Y}=\sum_{i=1}^{m} p_{i} y\left(w_{i}\right) A_{i}
$$

where $\bar{Y}$ is the total field yield, $A_{i}$ the area in the $i$ th section of the field, $m$ the total number of area sections of the field, $p_{i}$ the percent of land receiving $w_{i}$ depth of irrigation water, $w_{i}$ the depth of application received by the $i$ th area increment and $y\left(w_{i}\right)$ is the functional relationship between yield and depth of applied water.

Most yield-water relationships indicate a curvilinear yield-water trend where yields first tend to increase linearly with increasing amounts of water and then the yield response to increasing increments decreases until there is no further response to additional water. Yields sometimes decrease when excessive water is applied. Grimes et $a .^{39,40}$ studied the yield of cotton as a function of water and nitrogen and found that increasing increments of water resulted in a curvilinear (quadratic) lint yield response on both a fine, sandy-loam and a clay-loam soils. They reported that the relationship between water and nitrogen on the one hand and cotton quality on the other was described quite well by a second-degree polynomial. Empirically, $y\left(w_{i}\right)$ was estimated in this work with the following quadratic relationship obtained in Central Arizona by Bucks et al: ${ }^{38}$

$$
\frac{y_{i}}{y_{m}}=-1.56+\left(\frac{\sum_{j=1}^{n} w_{i j}}{E T_{m}}\right)-2.59\left(\frac{\sum_{j=1}^{n} w_{i j}}{E T_{m}}\right)^{2}
$$

where $j$ represents the number of irrigations per season, $i$ the fractional area, $w_{i j}$ the amount of infiltrated water that supports $E T$ in the $i$ th area and $E T_{m}$ and $y_{m}$ the maximum crop-evapotranspiration and yield. ${ }^{14}$ When the $E T$ requirement is solely supplied by irrigation, $E T_{m}$ is the maximum water application $\left(w_{m}\right)$ for maximum yield, and in non-uniform application sites, cotton yields decline where $w_{i j} \neq E T_{m}$. Excess water can lead to poor soil aeration and/or fertilizer leaching, both impeding plant growth and reducing yields. In these areas of the field decrease in cotton lint up to 0.2 of maximum yield ${ }^{6}$ $(1.6 \mathrm{t} / \mathrm{ha})$ were assumed. Although somewhat arbitrary, this condition is more realistic than the zero yield predicted by the quadratic equation. The irrigation depths stored in the different sections (sites) of the field and the yield function of Eqn (6), weighted to account for the areas, are linked in a computer program to calculate the spatial mean cotton yield.

\section{Reference ET estimates}

A common practice in irrigated agriculture is to use climatic data for determining mean crop water requirement. Evapotranspiration of a particular crop $\left(E T_{\text {crop }}\right)$ is related to the potential $E T\left(E T_{0}\right)$ through the relationship, $E T_{\text {crop }}=K_{c} E T_{0}$, where $K_{c}$ is the crop coefficient that accounts for the effect of crop characteristics on crop water requirements.

Of the many uncertainties facing the cotton grower, perhaps the most uncertain factor is weather. $E T_{\text {crop }}$ will exhibit within- and between-year variation making 
estimates of water requirements very tenuous for the decision maker. It can be argued that irrigators make decisions based on their subjective estimates of probable $E T_{\text {crop }}$ outcomes. These subjective estimates by the grower are formulated through historical weather records, expert opinion and personal experience.

Young ${ }^{41}$ has evaluated the necesary criteria or guidelines for using objective probabilities as substitutes for subjective assessments. First, the variability measure (Var) should be an appropriately weighted mean-square forecast error from a series of one-step ahead forecasts approximated by the expression

$$
\operatorname{Var}(x)=\sum_{t=1}^{n} b_{t}\left(X_{t}-\bar{X}_{t}\right)^{2}
$$

where $n$ is the number of time-ordered observations of the variable $(X), b_{t}$ the mathematical probability weight for the period $t$ where $\sum b_{t}=1$ and $0 \leqslant b_{t} \leqslant 1$ and $\bar{X}_{t}$ the expectation of $X_{t}$ generated in period $(t-1)$ when the decision must be made. Second, the expectation for period $t$ should use only information available at the time the expectation is formed, i.e. only information from periods $1, \ldots, t-1$. A third criterion is based on the recognition that decision makers are likely to consider information from past periods obsolete after a certain time. Therefore, the calculation of $V$ ar should incorporate information from a limited number of past periods. Since growers are likely to give greater weight to recent events in formulating subjective probability estimates, a fourth guideline is that more recent information should be given greater weight in computing $V$ ar and expected values of $X$. Finally, both $\bar{X}_{t}$ and $V$ ar should be updated frequently, preferably each period. This criterion recognizes the principle that decision makers update their subjective probability assessments as new information becomes available.

Young's guidelines were used to estimate the probable expected mean $E T_{\text {crop }}$ outcomes needed to define the seasonal average water application requirement in the low-quarter and ultimately the seasonal number of surface irrigations. Historical seasonal $E T_{0}$ time series between 1969 and 1987 were calculated for a Central Arizona cotton farm using the Penman method, $K_{c}$ 's and daily weather values from the Mesa Agricultural Experimental Station near Phoenix, Arizona (USA). These values are given in Table 2. To estimate the probable expected $E T_{\text {crop }}$ outcome for a given year, the following descending weighted moving-average technique was

Table 2

Crop evapotranspiration $(\mathrm{mm})$ for the growth period of cotton in Central Arizona

Cotton stages of development

\begin{tabular}{|c|c|c|c|c|c|c|c|c|c|c|}
\hline \multirow[b]{4}{*}{ Year } & \multicolumn{2}{|c|}{ Initial } & \multicolumn{2}{|c|}{ Development } & \multicolumn{2}{|c|}{ Mid-season } & \multicolumn{2}{|c|}{ Late-season } & \multirow[b]{2}{*}{$\begin{array}{l}1-15 \\
\text { Nov. }\end{array}$} & \multirow[b]{4}{*}{$E T_{\text {crop }} m m$} \\
\hline & April & May & June & $\begin{array}{l}\text { 1-15 } \\
\text { July }\end{array}$ & $\begin{array}{c}16-31 \\
\text { July }\end{array}$ & Aug. & Sept. & Oct. & & \\
\hline & \multicolumn{9}{|c|}{ Crop coefficient $\left(K_{c}\right)$} & \\
\hline & $0 \cdot 25$ & $0 \cdot 25$ & 0.53 & 0.98 & $1 \cdot 15$ & $1 \cdot 15$ & $1 \cdot 03$ & $0 \cdot 78$ & 0.58 & \\
\hline 1969 & 46 & 54 & 124 & 120 & 150 & 289 & 189 & 98 & 25 & 1092 \\
\hline 1970 & 53 & 66 & 129 & 128 & 161 & 259 & 172 & 92 & 21 & 1080 \\
\hline 1971 & 43 & 52 & 112 & 123 & 154 & 244 & 170 & 91 & 19 & 1007 \\
\hline 1972 & 47 & 54 & 117 & 121 & 153 & 255 & 175 & 74 & 20 & 1016 \\
\hline 1973 & 47 & 62 & 130 & 123 & 155 & 207 & 175 & 94 & 20 & 1011 \\
\hline 1974 & 47 & 58 & 133 & 115 & 144 & 272 & 184 & 89 & 21 & 1063 \\
\hline 1975 & 45 & 54 & 117 & 114 & 144 & 244 & 178 & 91 & 20 & 1006 \\
\hline 1976 & 45 & 55 & 118 & 115 & 144 & 245 & 180 & 91 & 20 & 1012 \\
\hline 1977 & 50 & 57 & 131 & 121 & 152 & 265 & 181 & 92 & 21 & 1070 \\
\hline 1978 & 46 & 57 & 126 & 119 & 149 & 250 & 177 & 92 & 21 & 1036 \\
\hline 1979 & 45 & 50 & 119 & 111 & 140 & 226 & 169 & 81 & 19 & 960 \\
\hline 1980 & 43 & 50 & 107 & 110 & 138 & 223 & 155 & 80 & 17 & 921 \\
\hline 1981 & 46 & 55 & 118 & 109 & 138 & 234 & 164 & 85 & 20 & 968 \\
\hline 1982 & 41 & 52 & 107 & 107 & 134 & 235 & 169 & 77 & 18 & 939 \\
\hline 1983 & 41 & 57 & 123 & 113 & 142 & 208 & 173 & 83 & 16 & 956 \\
\hline 1984 & 39 & 58 & 103 & 97 & 123 & 214 & 171 & 86 & 20 & 911 \\
\hline 1985 & 41 & 60 & 124 & 122 & 153 & 257 & 176 & 94 & 22 & 1048 \\
\hline 1986 & 47 & 50 & 130 & 118 & 148 & 268 & 176 & 90 & 23 & 1060 \\
\hline 1987 & 55 & 53 & 132 & 119 & 149 & 247 & 171 & 106 & 24 & 1055 \\
\hline
\end{tabular}

Data source: Mesa Experimental Farm, Central Arizona. 
Table 3

Mean expected crop evapotranspiration for cotton

\begin{tabular}{ccc}
\hline Year & $\begin{array}{c}\text { Time period } \\
\text { used for estimation }\end{array}$ & $\begin{array}{c}\text { ET cotton } \\
\mathrm{mm}\end{array}$ \\
1979 & $1969-1978$ & 1040 \\
1980 & $1970-1979$ & 1000 \\
1981 & $1971-1980$ & 960 \\
1982 & $1972-1981$ & 960 \\
1983 & $1973-1982$ & 950 \\
1984 & $1974-1983$ & 950 \\
1985 & $1975-1984$ & 930 \\
1986 & $1976-1985$ & 990 \\
1988 & $1977-1986$ & 1020 \\
& $1978-1987$ & 1040 \\
\hline
\end{tabular}

applied using $10 \mathrm{yr}$ of data prior to the year being predicted. The average of the immediately previous $n$ years that represent the expected component for year $t$ is calculated as

$$
\bar{X}_{t}=\sum_{i=1}^{n} b_{i} X_{i}
$$

and $b_{i}$ the probability weight for each year

$$
b_{i}=\frac{0 \cdot 5^{i}}{\sum_{j=1}^{n} 0 \cdot 5^{i}}
$$

Weights decline from the most recent to the most distant years to recognize the greater importance of more recent events. The results obtained are presented in Table 3 where for each year the earliest observation is dropped and the most recent period is added.

\section{Estimated applied water and crop yields}

Figure 4 gives example of the spatial applied water and cotton yield obtained for level basin and drip irrigation on Casa-Grande soil. The required input data for the simulation are given in Table 4.

Table 4

Required input data for the simulation presented in Fig. 4.

\section{Year}

Maximum crop evapotranspiration

Area adequately irrigated

Christiansen uniformity coefficient

Level basin

Drip

Seasonal infiltrated depth

Level basin

Drip
1988

$1039 \mathrm{~mm}$

$87 \cdot 5 \%$

$0 \cdot 89$

$0 \cdot 88$

$1259 \mathrm{~mm}$

$1228 \mathrm{~mm}$

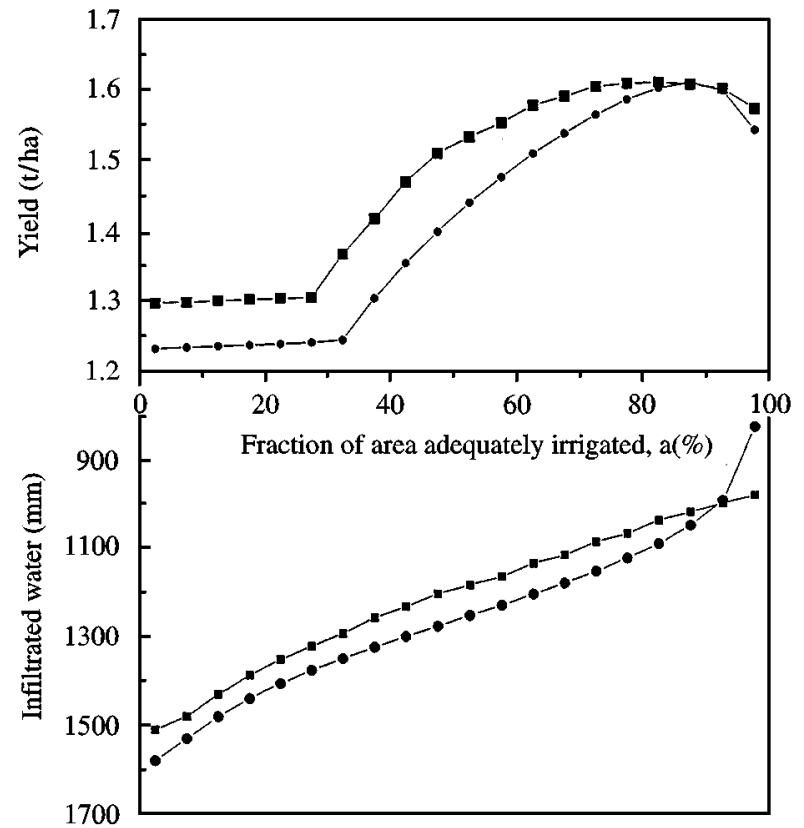

Fig. 4. Relationships between crop yield and infiltrated water for drip (O) and level basin (ם) irrigated cotton fields simulated with the model described by Fig. 1. The seasonal amount of applied and infiltrated depths at different sections of the irrigated fields are related to spatially varied yields through a specific crop-water production function. Both irrigation technologies adequately irrigate a similar fraction of the fields (average of the low-quarter) with the required depth of water applicaiton

The simulated yield values verify reported field data collected for Maricopa Agriculture Center, a University of Arizona research and demonstration centre in Central Arizona. ${ }^{6,42,43}$ The same procedure can be used for other uniformity levels and assumptions of area adequately irrigated.

Table 5 gives a summary of the estimated cotton yield and seasonal water applied for the four types of irrigation systems (grad furrow, level furrow, level basin and drip) under the two management options over a $10 \mathrm{yr}$ period. As in Fig. 4, the results obtained show that comparable yields are obtained for surface and drip irrigation systems when irrigation management decisions are taken which allow these systems to infiltrate comparable seasonal water depths in the root zone and to irrigate similar fractions of the fields. The applied water and simulated yields provide required information for evaluation of irrigation technologies and valuable input for the adoption of irrigation decision models. With comparable yields, the superiority of one system over another is merely the result of too much or too little water applied. 
Table 5

Seasonal water applied and cotton yields for alternative irrigation technologies and management options

\begin{tabular}{|c|c|c|c|c|c|c|c|c|c|c|}
\hline \multirow[b]{3}{*}{ Year } & \multicolumn{10}{|c|}{ Irrigation management option I } \\
\hline & \multicolumn{2}{|c|}{ Graded furrow } & \multicolumn{2}{|c|}{ Level furrow } & \multicolumn{2}{|c|}{ Level basin } & \multicolumn{2}{|c|}{ Drip $(94 \% U C C)$} & \multicolumn{2}{|c|}{ Drip $(96 \% U C C)$} \\
\hline & $\begin{array}{c}\text { Depth } \\
\text { cm }\end{array}$ & $\begin{array}{c}\text { Yield } \\
\text { t/ha }\end{array}$ & $\begin{array}{c}\text { Depth } \\
\text { cm }\end{array}$ & $\begin{array}{l}\text { Yield } \\
\text { t/ha }\end{array}$ & $\begin{array}{c}\text { Depth } \\
\mathrm{cm}\end{array}$ & $\begin{array}{l}\text { Yield } \\
\text { t/ha }\end{array}$ & $\begin{array}{c}\text { Depth } \\
\mathrm{cm}\end{array}$ & $\begin{array}{l}\text { Yield } \\
\text { t/ha }\end{array}$ & $\begin{array}{c}\text { Depth } \\
\mathrm{cm}\end{array}$ & $\begin{array}{l}\text { Yield } \\
\text { t/ha }\end{array}$ \\
\hline 1979 & 277 & $1 \cdot 56$ & 229 & $1 \cdot 39$ & 123 & $1 \cdot 43$ & 114 & $1 \cdot 53$ & 110 & $1 \cdot 57$ \\
\hline 1980 & 277 & $1 \cdot 53$ & 229 & $1 \cdot 37$ & 123 & $1 \cdot 39$ & 110 & $1 \cdot 53$ & 106 & $1 \cdot 57$ \\
\hline 1981 & 252 & $1 \cdot 57$ & 208 & $1 \cdot 40$ & 112 & $1 \cdot 44$ & 105 & $1 \cdot 53$ & 102 & $1 \cdot 57$ \\
\hline 1982 & 252 & $1 \cdot 58$ & 208 & $1 \cdot 40$ & 112 & $1 \cdot 44$ & 106 & $1 \cdot 53$ & 102 & $1 \cdot 57$ \\
\hline 1983 & 252 & $1 \cdot 57$ & 208 & $1 \cdot 39$ & 112 & $1 \cdot 43$ & 104 & $1 \cdot 53$ & 101 & $1 \cdot 57$ \\
\hline 1984 & 252 & $1 \cdot 57$ & 208 & $1 \cdot 39$ & 112 & $1 \cdot 43$ & 104 & $1 \cdot 53$ & 101 & $1 \cdot 57$ \\
\hline 1985 & 252 & $1 \cdot 55$ & 208 & $1 \cdot 38$ & 112 & $1 \cdot 41$ & 102 & $1 \cdot 53$ & 99 & $1 \cdot 57$ \\
\hline 1986 & 252 & $1 \cdot 59$ & 208 & $1 \cdot 41$ & 112 & $1 \cdot 47$ & 108 & $1 \cdot 53$ & 105 & $1 \cdot 57$ \\
\hline 1987 & 277 & $1 \cdot 55$ & 229 & $1 \cdot 38$ & 123 & $1 \cdot 41$ & 112 & $1 \cdot 53$ & 109 & $1 \cdot 57$ \\
\hline 1988 & 277 & $1 \cdot 56$ & 229 & $1 \cdot 39$ & 123 & $1 \cdot 43$ & 114 & $1 \cdot 53$ & 110 & $1 \cdot 57$ \\
\hline
\end{tabular}

Irrigation management option II

\begin{tabular}{|c|c|c|c|c|c|c|c|c|c|c|}
\hline \multirow[b]{2}{*}{ Year } & \multicolumn{2}{|c|}{ Graded furrow } & \multicolumn{2}{|c|}{ Level furrow } & \multicolumn{2}{|c|}{ Level basin } & \multicolumn{2}{|c|}{ Drip $(88 \%$ UCC) } & \multicolumn{2}{|c|}{ Drip $(92 \% U C C)$} \\
\hline & $\begin{array}{c}\text { Depth } \\
\text { cm }\end{array}$ & $\begin{array}{l}\text { Yield } \\
\text { t/ha }\end{array}$ & $\begin{array}{c}\text { Depth } \\
\mathrm{cm}\end{array}$ & $\begin{array}{l}\text { Yield } \\
\text { t/ha }\end{array}$ & $\begin{array}{c}\text { Depth } \\
\mathrm{cm}\end{array}$ & $\begin{array}{l}\text { Yield } \\
\text { t/ha }\end{array}$ & $\begin{array}{c}\text { Depth } \\
\text { cm }\end{array}$ & $\begin{array}{l}\text { Yield } \\
\text { t/ha }\end{array}$ & $\begin{array}{c}\text { Depth } \\
\text { cm }\end{array}$ & $\begin{array}{c}\text { Yield } \\
\text { t/ha }\end{array}$ \\
\hline 1979 & 195 & $1 \cdot 48$ & 183 & $1 \cdot 37$ & 141 & $1 \cdot 35$ & 126 & $1 \cdot 41$ & 118 & $1 \cdot 48$ \\
\hline 1980 & 195 & $1 \cdot 44$ & 183 & $1 \cdot 36$ & 141 & $1 \cdot 34$ & 121 & $1 \cdot 41$ & 113 & $1 \cdot 48$ \\
\hline 1981 & 178 & $1 \cdot 50$ & 166 & $1 \cdot 37$ & 128 & $1 \cdot 36$ & 116 & $1 \cdot 41$ & 109 & $1 \cdot 48$ \\
\hline 1982 & 178 & $1 \cdot 50$ & 166 & $1 \cdot 37$ & 128 & $1 \cdot 36$ & 117 & $1 \cdot 41$ & 109 & $1 \cdot 48$ \\
\hline 1983 & 178 & $1 \cdot 49$ & 166 & $1 \cdot 37$ & 128 & $1 \cdot 35$ & 117 & $1 \cdot 41$ & 108 & $1 \cdot 48$ \\
\hline 1984 & 178 & $1 \cdot 49$ & 166 & $1 \cdot 37$ & 128 & $1 \cdot 35$ & 116 & $1 \cdot 41$ & 108 & $1 \cdot 48$ \\
\hline 1985 & 178 & $1 \cdot 46$ & 166 & $1 \cdot 36$ & 128 & $1 \cdot 35$ & 113 & $1 \cdot 41$ & 105 & $1 \cdot 48$ \\
\hline 1986 & 178 & $1 \cdot 53$ & 166 & $1 \cdot 38$ & 128 & $1 \cdot 36$ & 120 & $1 \cdot 41$ & 112 & $1 \cdot 48$ \\
\hline 1987 & 195 & $1 \cdot 46$ & 183 & $1 \cdot 36$ & 141 & $1 \cdot 35$ & 124 & $1 \cdot 41$ & 116 & $1 \cdot 48$ \\
\hline 1988 & 195 & $1 \cdot 48$ & 183 & $1 \cdot 37$ & 141 & $1 \cdot 35$ & 126 & $1 \cdot 41$ & 118 & $1 \cdot 48$ \\
\hline
\end{tabular}

\section{Conclusions}

This paper tested the suitability of a comprehensive simulation model to provide objective comparison of alternative irrigation technologies by simulating their performance in terms of applied water and crop yield. Meaningful and comparable yields and infiltrated water were obtained when comparable assumptions of water application uniformity and fraction of the field area adequately irrigated were assumed.

The model used an empirical application of Strelkoffs' SRFR model, management-design charts and a pressurized distribution-uniformity model, coupled with a crop yield-water function. In application, the choices of $U C C$ and $L Q$ depth of application are critical, and they must be carefully chosen, especially the combined values from the management chart in Fig. 2, and from the statistical table of Hart and Reynolds. ${ }^{32}$ Provisions should be made to infiltrate equal seasonal water depth in a similar fraction of the field (here the low-quarter) and irrigate similar crop land. For furrow irrigation systems, other provisions should be made to ensure irrigation practices of the cut-back type and return-flow systems to recover the runoff flows, and improve irrigation efficiencies.

Another important feature of the procedure is to calculate $E T_{\text {crop }}$ for a long planning period using Young's criteria for subjective probability estimates from objective data. These calculations provide additional realism for the predicted results by more accurately simulating crop water requirement decisions that must be made by the farmer.

The results suggest that the approach is useful to explore feature implications of design decisions for irrigation systems. 


\section{References}

1 Solomon K H Irrigation system selection. Irrigation Notes 1988. Centre for Irrigation Technology, California State University, CA

2 Nakayama F S; Bucks D A Trickle Irrigation for Crop Producton: Design Operation and Management. Amsterdam: Elsevier, 1986

3 Hill R W; Keller J Irrigation system selection for maximum crop profit. Transactions of the ASAE, 1980, 23, 366-372

${ }^{4}$ Hanson B R A systems approach to drainage reduction. California Agriculture, 1987, 41, 9 and 10

5 Hansen E G; Patterson T C Vegetable production and water use efficiencies as influenced by drip, sprinkler, subsurface and furrow irrigation methods. Proceedings of 2nd International Drip Irrigation Congress, San Diego, CA, 1974, 97-102

6 Santos F L Optimal irrigation system selection: a multiperiod quadratic programming approach. $\mathrm{PhD}$ thesis, University of Arizona, Tucson, AZ, USA, 1990

7 Santos F L Evaluation and adoption of irrigation technologies. I. Management-design charts for furrow and levelbasin systems. Agricultural Systems, 1996, 52, 317-329

${ }^{8}$ Strelkoff T S SRFR - a model of surface irrigation - version 20. Proceedings of the National Conference Sponsored by the Irrigation and Drainage Division of the American Society of Civil Engineers and Hawaii Section, Honolulu, 1991, 676-682

9 Seginer I A note on the economic significance of uniform water application. Irrigation Science, 1978, 1, 19

10 Seginer I Irrigation uniformity effect on land and water allocation. Transactions of the ASAE, 1983, 26, 116

11 Seginer I Spatial water distribution in sprinkler irrigation. Advances in Irrigation, 1987, 4, 119-167

12 Warrick A W; Gardner W R Crop yield as affected by spatial variations of soil and irrigation. Water Resources Research, 1983, 19, 181-186

13 Letey J; Vaux Jr H J; Feinerman E Optimum crop water application as affected by uniformity of water infiltration. Agronomy Journal, 1987, 76, 435

${ }^{14}$ Yitayew M; Letey J; Vaux Jr H J; Feinerman E (1985) Factors affecting uniformity and optimal water management with furrow irrigation. Irrigation Science, 1985, 6, 201-210

15 Warrick A W; Yates S R Crop yield as influenced by irrigation uniformity. Advances in Irrigation, 1983, 4, 169-180

16 Stelkoff T S; Souza F Modelling effect of depth on furrow infiltration. Journal of Irrigation and Drainage Engineering, 1984, 110, 375-387

17 Solomon K Manufacturing variation of trickle emitters. Transactions of the ASAE, 1979, 22, 1034-1038

18 Wu I P; Gitlin H M Drip irrigation application efficiency and schedules. Transactions of the ASAE, 1983, 26, 92-99

19 Shatanawi M R; Strelkoff T Management contours for border irrigation. Journal of Irrigation and Drainage Engineering ASCE, 1984, 110, 393-399

20 Stewart J I; Hagan R M Functions to predict effects of crop water deficits. Journal of Irrigation and Drainage Division of the ASCE, 1973, 99, 421-439

21 Vaux H J; Pruitt W Crop-water production functions. Advances in Irrigation, 1983, 2, 61-93

${ }^{22}$ Stegman E C; Musick J T; Stewart J I Irrigation water management. In Design and Operation of Farm Irrigation Systems, 1980 Monograph, Vol. 3, Pp. 721-760. St. Joseph MI: ASAE
23 Doorenbos J; Pruitt W O Crop water requirements. Irrigation and Drainage Paper No. 24, Food and Agriculture Organisation of the United Nations, Rome, 1984

24 Arkley R J Relationship between plant growth and transpiration. Hilgardia, 1963, 34, 579-584

25 Strelkoff T S The one-dimensional equations of open channel flow. Journal of the Hydraulics Division ASCE, 1969, 95, 861-876

${ }^{26}$ Katopodes N D; Strelkoff T S Hydrodynamics of border irrigation - complete model. Journal of the Irrigation and Drainage Division ASAE, 1997, 103, 309-324

${ }^{27}$ de Sousa P L; Dedrick A R; Clemmens A J; Pereira L S Benefits and costs of laser-controlled levelling — a case study. In Water Management in the Next Century, Transactions of the 15th Congress on Irrigation and Drainage, 1993, Vol. 1c, Q44, R97, Pp. 1237-1247. New Delhi, India

${ }^{28}$ de Sousa P L; Dedrick A R; Clemmens A J; Pereira L S Effects of furrow elevation differences on level-basin performance. Transactions of the ASAE, 1995, 38, 153-158

${ }^{29}$ Hart W E; Collins H G; Woodward G; Humphrerys A S (1980) Design and operation of gravity or surface systems. In Design and Operation of Farm Irrigation Systems, Monograph, Vol. 3, Pp. 501-580. St. Joseph MI: ASAE

30 USDA Furrow irrigation. Soil Conservation Service National Engineering Handbook, Chapter 5, Section 15 (Irrigation), 1979

31 Kruse E G; Humpherys A S; Pope E J Design and operation of gravity or surface systems. In Design and Operation of Farm Irrigation System. Monography 3, p. 398. St. Joseph MI: ASAE

32 Hart W E; Reynolds W N Analytical design of sprinkler systems. Transactions of the ASAE, 1965, 9, 83-85, 89

33 Warrick A W; Hart W E; Yitayew M Calculation of distribution and efficiency for nonuniform irrigation. Journal of Irrigation and Drainage Division ASAE, 1989, 115, 674-686

${ }^{34}$ Heerman D F; Duke H R; Dawson L J Distribution functions to represent center pivot water distribution. ASAE 1991 Summer Meeting Paper 91-2051, St. Joseph MI, USA

35 Sammis T W; Wu I P Effect of drip irrigation design and management on crop yield. Transactions of the ASAE, 1985, 22, 832-838

36 Wu I P 1988 Optimal scheduling and minimizing deep seepage in microirrigation. Transactions of the ASAE, 1995, 38, 1385-1392

37 Doorendos J; Kassam A H Yield response to water 1979. FAO Irrigation and Drainage Paper No. 33, Food and Agriculture Organisation of the United Nations. Rome, Italy

38 Bucks D A; Nakayama F S; Warrick A W Principles, practices and potentialities of trickle (drip) irrigation. Advances in Irrigation, 1982, 3, 275-282

39 Grimes D W; Yamada H; Dickens W L Functions for cotton (Gossypium hirsutum L.) production from irrigation and nitrogen fertilisation variables. I. Yield and evapotranspiration. Agronomy Journal, 1969a, 2, 769-773

40 Grimes D W; Yamada H; Dickens W L G Functions for cotton (Gossypium hirsutum L.) production from irrigation and nitrogen fertilization variables. II. Yield components and quality characteristics. Agronomy Journal, 1969b, 61, 773-776 
41 Young D L Risk analysis in agriculture: research and educational developments. Proceedings of a Seminar sponsored by Western Regional Research Project W149, Tucson, Arizona, 16-18 January 1980

42 US Department of Agriculture, Economics and Statistics Agricultural Statistics Bulletins. Arizona crop and live- stock reporting service 1970-1987. University of Arizona, College of Agriculture, Tucson

43 Wilson P; Ayer H; Snider G Drip irrigation for cotton: implications for farm profits. Agricultural Economic Report 517, 1984, Economic Research Service, USDA, Washington, DC 